\title{
A phase I study of imatinib, dacarbazine, and capecitabine in advanced endocrine cancers
}

\author{
Daniel M Halperin ${ }^{1}$, Alexandria T Phan ${ }^{2}$, Ana O Hoff ${ }^{3}$, Marie Aaron$^{1}$, James C Yao ${ }^{1 *}$ and Paulo M Hoff ${ }^{4}$
}

\begin{abstract}
Background: Patients with advanced endocrine cancers, such as adrenocortical carcinoma and medullary thyroid carcinoma, have few well-validated therapeutic options. Pre-clinical studies have suggested potential activity of imatinib in these tumors. We therefore sought to establish a safe, novel treatment regimen combining imatinib with cytotoxic chemotherapy for future study in endocrine cancers.
\end{abstract}

Methods: A standard $3+3$ dose-escalation design was used with a 21-day cycle, including imatinib on days 1-21, dacarbazine on days 1-3, and capecitabine on days 1-14.

Results: Twenty patients were treated. The most frequent toxicities were edema and fatigue, with dose-limiting fatigue and dyspnea. The recommended phase II regimen is dacarbazine $250 \mathrm{mg} / \mathrm{m} 2$ daily on day $1-3$, capecitabine $500 \mathrm{mg} / \mathrm{m} 2$ twice daily on days $1-14$, and imatinib $300 \mathrm{mg}$ daily on days 1-21 of a 21-day cycle. Interestingly, responses were seen in patients with adrenocortical carcinoma, with 1 of 6 patients experiencing a partial response and a second experiencing a minor response, with progression-free survival of 8.8 and 6.4 months, respectively.

Conclusions: The regimen of imatinib, dacarbazine, and capecitabine is well-tolerated. It may have some activity in adrenocortical carcinoma, and further study of this combination or its components may be beneficial for this disease with limited treatment options.

Trial registration: ClinicalTrials.gov identifier NCT00354523, registered July 18, 2006.

\section{Background}

Endocrine cancers are a heterogeneous group of malignancies. Adrenocortical carcinoma (ACC) and medullary thyroid carcinoma (MTC) are challenging cancers to treat if metastatic or unresectable, and few chemotherapy regimens have proven effective for advanced disease.

Medullary thyroid carcinoma (MTC) is a rare tumor arising from the parafollicular $\mathrm{C}$ cells of the thyroid gland [1]. Approximately $75 \%$ of these tumors are sporadic and $25 \%$ are hereditary, associated with the multiple endocrine neoplasia type 2 syndrome (MEN2) [2]. Multiple endocrine neoplasia type 2 is an autosomal dominant syndrome caused by germline activating mutations of the RET proto-oncogene which encodes for RET, a receptor tyrosine kinase that modulates $\mathrm{C}$ cell proliferation and apoptosis [3-5]. Patients with sporadic MTC do not carry germline RET mutations, but $40 \%$ of their tumors

\footnotetext{
* Correspondence: jyao@mdanderson.org

'Department of Gastrointestinal Medical Oncology, The University of Texas

M. D. Anderson Cancer Center, Houston, Texas, USA

Full list of author information is available at the end of the article
}

carry a somatic RET mutation, most commonly involving exon 16, conferring a more aggressive phenotype [6-9]. In vitro and in vivo studies of the most common germline and somatic RET mutations have established their role in oncogenesis [10-13]. In vitro studies using a MTC cell line with a RET codon 634 mutation demonstrated growth inhibition with imatinib, offering some hope that the drug may have efficacy in this tumor [14].

Systemic cytotoxic chemotherapy for advanced MTC has shown limited tumor response efficacy. Small trials studying dacarbazine, 5-fluorouracil, and doxorubicin [15-20], used alone or in combination, have demonstrated partial biochemical and tumor responses in 10-20\% of patients. More recently, inhibitors of the RET kinase, such as vandetanib [21] and cabozantinib [22], have shown evidence of significant progression- free survival benefit, and hence are FDA-approved for the treatment of patients with advanced MTC.

Adrenocortical carcinoma (ACC) is another rare malignancy of neuroectodermal origin with limited therapeutic options. It has an annual incidence of $1-2$ cases 
Table 1 Dose levels

\begin{tabular}{lllllll}
\hline Level & Imatinib & Dacarbazine & Capecitabine & Patients (N) & Dose reductions (N) & DLTs $^{\mathbf{1}}$ (N and type) \\
\hline $\mathbf{- 1}$ & $300 \mathrm{mg}$ & $250 \mathrm{mg} / \mathrm{m} 2$ & $500 \mathrm{mg} / \mathrm{m} 2 \mathrm{BID}$ & 6 & 0 & 1 (fatigue) \\
$\mathbf{1}$ & $400 \mathrm{mg}$ & $250 \mathrm{mg} / \mathrm{m} 2$ & $500 \mathrm{mg} / \mathrm{m} 2 \mathrm{BID}$ & 6 & 2 & 9 (Dyspnea, Fatigue, Diarrhea, Dehydration, Nausea, \\
& & & & & Ocular Surface Disease, Insomnia) \\
$\mathbf{2}$ & $400 \mathrm{mg}$ & $330 \mathrm{mg} / \mathrm{m} 2$ & $750 \mathrm{mg} / \mathrm{m} 2 \mathrm{BID}$ & 6 & 1 & 2 (Hypokalemia, platelets) \\
$\mathbf{3}$ & $400 \mathrm{mg}$ & $330 \mathrm{mg} / \mathrm{m} 2$ & $1000 \mathrm{mg} / \mathrm{m} 2 \mathrm{BID}$ & 0 & 0 & \\
$\mathbf{4}$ & $600 \mathrm{mg}$ & $330 \mathrm{mg} / \mathrm{m} 2$ & $1000 \mathrm{mg} / \mathrm{m} 2 \mathrm{BID}$ & 0 & 0 & \\
$\mathbf{5}$ & $800 \mathrm{mg}$ & $330 \mathrm{mg} / \mathrm{m} 2$ & $1000 \mathrm{mg} / \mathrm{m} 2 \mathrm{BID}$ & 0 & 0 &
\end{tabular}

Dose levels specified for protocol therapy. 1: DLTs - dose-limiting toxicities.

per million population [23,24], and a median overall survival that decreases dramatically as a function of clinical stage, ranging from over 10 years for stage I disease to less than 6 months with advanced stage [24]. Most cases are sporadic, but associations have been demonstrated with Li Fraumeni syndrome, Beckwith-Wiedemann syndrome, and MEN 1 [25,26]. While mitotane has been the mainstay of therapy since it was demonstrated to reduce serum and urine steroid concentrations in over $70 \%$ of patients in 1966 [27], high-quality clinical evidence for a survival benefit with any therapy was absent until a recent trial demonstrated the utility of etoposide, doxorubicin, cisplatin, and mitotane (EDP-mitotane) [28]. Molecularly targeted therapies have been of interest [29-31], but none have yet proven successful. Of particular interest was a study demonstrating that adrenocortical carcinomas express cKit and/or the PDGF receptor at some frequency, but are unresponsive to single-agent imatinib [32].

Therefore, MTC and ACC require more effective therapy. As most MTCs have upregulated RET activity and pre-clinical studies using imatinib inhibit MTC cell proliferation and induce apoptosis, this drug has been appealing for treating this disease. ACC could also theoretically respond to imatinib, perhaps when combined with additional chemotherapy to allow for cytotoxicity. We therefore undertook a phase I doseescalation trial of the combination of imatinib, dacarbazine, and capecitabine in advanced endocrine tumors, including predominantly patients with MTC and ACC.

\section{Methods}

\section{Inclusion criteria}

Men and women of all ethnic groups were eligible if they were $>16$ years old with an ECOG performance status of $0-2$ and any proven solid tumor for which no curative or standard treatment was available, regardless of prior therapy. Patients needed laboratory evidence of adequate hepatic, renal, and bone marrow function, as well as a negative pregnancy test (if applicable) and an agreement to use barrier contraception throughout therapy.

\section{Exclusion criteria}

Patients were ineligible if they had received chemotherapy or surgery within the last 3 weeks, or radiation within the last 4 weeks. Patients could not have received prior treatment with investigational agents within 28 days of study entry. Severe concurrent illness or ongoing pregnancy or lactation resulted in exclusion, as well. Patients with any other malignancy, except non-melanoma skin cancer or an MEN2-associated cancer, within the prior 5 years were also ineligible. Finally, patients could not be receiving warfarin during the study, though heparin products were allowed.

Table 2 Baseline patient characteristics

\begin{tabular}{ll}
\hline & Number (\%) \\
\hline Gge (Median) & 52 \\
Male & $12(60)$ \\
Diagnosis & \\
MTC $^{\mathbf{1}}$ & $7(35)$ \\
ACC $^{\mathbf{2}}$ & $5(25)$ \\
NET $^{3}$ & $3(25)$ \\
Melanoma $^{\mathbf{T}}$ & $1(5)$ \\
TCC $^{\mathbf{4}}$ & $1(5)$ \\
Prior therapy & $19(95)$ \\
Surgery & $16(80)$ \\
Radiation & $10(50)$ \\
Chemotherapy & $16(80)$ \\
Prior lines of chemotherapy & \\
$\mathbf{0}$ & $4(20)$ \\
$\mathbf{1}$ & $5(25)$ \\
$\mathbf{2}$ & $4(20)$ \\
$\mathbf{2}$ & $7(35)$ \\
\hline
\end{tabular}

Characteristics of patients enrolled on the study. Total $n=20 .^{1} \mathrm{MTC}$ - medullary thyroid carcinoma; ${ }^{2} \mathrm{ACC}$ - adrenocortical carcinoma; ${ }^{3} \mathrm{NET}$ - neuroendocrine tumor; ${ }^{4}$ Transitional cell carcinoma. 
Table 3 Adverse events

\begin{tabular}{|c|c|c|c|c|c|}
\hline Toxicity & G1 & G2 & G3 & G4 & Total \\
\hline Allergic rhinitis & 2 & 1 & 0 & 0 & 3 \\
\hline Alopecia & 2 & 0 & 0 & 0 & 2 \\
\hline$A L T^{1}$ & 1 & 0 & 1 & 0 & 2 \\
\hline Anorexia & 2 & 4 & 0 & 0 & 6 \\
\hline $\mathrm{AST}^{2}$ & 1 & 0 & 0 & 0 & 1 \\
\hline Bilirubin & 1 & 0 & 0 & 0 & 1 \\
\hline Cardiac ischemia & 0 & 0 & 1 & 0 & 1 \\
\hline Chest tightness & 1 & 0 & 0 & 0 & 1 \\
\hline Constipation & 4 & 4 & 0 & 0 & 8 \\
\hline Dehydration & 0 & 0 & 1 & 0 & 1 \\
\hline Diarrhea & 5 & 2 & 1 & 0 & 8 \\
\hline Distension & 0 & 0 & 1 & 0 & 1 \\
\hline Dizziness & 2 & 0 & 0 & 0 & 2 \\
\hline Dry mouth & 1 & 0 & 0 & 0 & 1 \\
\hline Dry skin & 1 & 0 & 0 & 0 & 1 \\
\hline Dysphagia & 1 & 0 & 0 & 0 & 1 \\
\hline Dyspnea & 2 & 2 & 6 & 0 & 10 \\
\hline Edema & 12 & 1 & 0 & 0 & 13 \\
\hline Fatigue & 5 & 3 & 5 & 0 & 13 \\
\hline Fever (no neutropenia) & 1 & 0 & 0 & 0 & 1 \\
\hline Flushing & 1 & 0 & 0 & 0 & 1 \\
\hline Hand-foot syndrome & 1 & 0 & 0 & 0 & 1 \\
\hline Hemoglobin & 1 & 2 & 0 & 0 & 3 \\
\hline Hypocalcemia & 1 & 0 & 0 & 0 & 1 \\
\hline Hypokalemia & 2 & 0 & 2 & 0 & 4 \\
\hline Hypomagnesemia & 1 & 0 & 0 & 0 & 1 \\
\hline Insomnia & 2 & 5 & 1 & 0 & 8 \\
\hline Mood alteration & 0 & 1 & 0 & 0 & 1 \\
\hline Mucositis & 4 & 0 & 0 & 0 & 4 \\
\hline Nausea & 4 & 6 & 1 & 0 & 11 \\
\hline Neuropathy (sensory) & 3 & 2 & 0 & 0 & 5 \\
\hline Neutrophils & 0 & 2 & 1 & 0 & 3 \\
\hline Ocular surface disease & 1 & 1 & 1 & 0 & 3 \\
\hline Ocular/visual & 2 & 0 & 0 & 0 & 2 \\
\hline Pain & 12 & 6 & 1 & 0 & 19 \\
\hline Palpitations & 1 & 0 & 0 & 0 & 1 \\
\hline Platelets & 1 & 0 & 0 & 0 & 1 \\
\hline Pleural effusion & 1 & 0 & 0 & 0 & 1 \\
\hline Pruritis & 1 & 0 & 0 & 0 & 1 \\
\hline Rash & 6 & 0 & 0 & 0 & 6 \\
\hline Rigors/chills & 2 & 0 & 0 & 0 & 2 \\
\hline Sinus tachycardia & 1 & 0 & 0 & 0 & 1 \\
\hline Somnolence & 3 & 0 & 0 & 0 & 3 \\
\hline Sweating & 1 & 0 & 0 & 0 & 1 \\
\hline
\end{tabular}

Table 3 Adverse events (Continued)

\begin{tabular}{llllll}
\hline Taste alteration & 5 & 4 & 0 & 0 & 9 \\
Upper respiratory infection & 1 & 0 & 0 & 0 & 1 \\
Voice change & 2 & 0 & 0 & 0 & 2 \\
Vomiting & 2 & 2 & 0 & 0 & 4 \\
Watery eye & 1 & 0 & 0 & 0 & 1 \\
Adverse events reported according to the Cancer Therapy Evaluation Program \\
Common Toxicity Criteria, version 3.0. 1: ALT - alanine aminotransferase \\
elevation; 2: AST - aspartate aminotransferase elevation. \\
Design
\end{tabular}

All patients provided written informed consent meeting M.D. Anderson Cancer Center Institutional Review Board (IRB) and NCI standards.

The study was designed as a single-arm, open-label dose-escalation study of imatinib, dacarbazine, and capecitabine. Imatinib was given orally on days $1-21$, dacarbazine was given intravenously over 1 hour on Days 1-3, and capecitabine was given orally twice daily on days $1-14$. A cycle of treatment was defined as 21 days with the next cycle starting on Day 22. A standard $3+3$ dose-escalation scheme was utilized (Table 1).

The objective of the trial was to determine the maximum tolerated dose (MTD) of the combination of imatinib, dacarbazine, and capecitabine. Toxicities were graded according to the Cancer Therapy Evaluation Program Common Toxicity Criteria, version 3.0. MTD was defined as the dose level below that producing dose-limiting toxicity (DLT; i.e. any Grade 4 hematologic toxicity and /or non-hematologic toxicity $\geq$ Grade 3 except alopecia within the first 28 days) in $\geq 33 \%$ of patients.

Baseline cross-sectional imaging by computed tomography or magnetic resonance imaging was performed within 28 prior to study enrollment, and response to treatment was measured using the modified RECIST criteria with radiological evaluation every 9 weeks.

Treatment continued until occurrence of disease progression, unacceptable toxicity, or the patient elected to discontinue study participation.

The study was conducted in concordance with the Declaration of Helsinki and approved by the MD Anderson Cancer Center Institutional Review Board as protocol 2004-0475.

\section{Statistical considerations}

Median progression-free survival (PFS) and overall survival (OS) were calculated by the Kaplan-Meier method. Follow-up was calculated from date of study enrollment until date of last contact. All statistical analyses were performed using SPSS version 21.0. 


\section{Results}

\section{Patient demographics}

From January 2005 through September 2006, 21 patients were screened and 20 patients were enrolled. Their median age was 52 years (range 33-77 years) (Table 2). Two patients did not complete the first cycle of protocol therapy due to symptomatic or progressive disease, and were excluded from analysis for DLT. The patient population was enriched for patients with MTC and ACC, but also included patient with pancreatic neuroendocrine tumors, melanoma, and transitional cell carcinoma. All patients were metastatic at time of therapy initiation.

\section{Dose escalation and maximum tolerated dose}

An initial cohort of three patients was enrolled at dose level 1 (dacarbazine $250 \mathrm{mg} / \mathrm{m} 2$, capecitabine $1000 \mathrm{mg} / \mathrm{m} 2$ twice daily, and imatinib $400 \mathrm{mg}$ ) without observing a DLT. The next cohort of three patients was treated at dose level 2, with one patient experiencing grade 3 hypokalemia. An additional three patients were enrolled at this dose level, with one experiencing grade 3 thrombocytopenia. Therefore, three additional patients were enrolled at dose level 1 , with all patients experiencing a grade 3 toxicity, including 2 patients with dyspnea and 2 with fatigue. When the next cohort of three patients was enrolled in dose level -1 , a single patient experienced grade 3 fatigue. The final cohort of three patients enrolled in dose level -1 and experienced no DLT.

\section{Safety}

The most common toxicities for all cycles were fatigue and edema, each occurring in $65 \%$ of patients (Table 3). Edema was mostly grade 1, but $25 \%$ of patients described grade 3 fatigue during treatment. The most common grade 3 adverse event was dyspnea, with $30 \%$ of patients describing that symptom. Most treatment-related adverse effects were transient, and only one patient required dose reduction.

\section{Tumor responses}

Overall, 18 of 20 patients reached first restaging. The remaining two had expired from progressive disease. Of those 18 patients, 12 had progressive disease, 6 had stable disease, 1 had a minor response, and 1 had a confirmed partial response as best response to protocol therapy. Intriguingly, both of the responses were seen in patients with ACC, despite both of these patients being

Table 4 Patient outcomes

\begin{tabular}{|c|c|c|c|c|c|c|c|c|c|}
\hline Patient & Diagnosis & $\begin{array}{l}\text { PD at } \\
\text { entry }\end{array}$ & $\begin{array}{l}\text { Prior } \\
\text { chemo }\end{array}$ & $\begin{array}{c}\text { Prior } \\
\text { surgery }\end{array}$ & $\begin{array}{l}\text { Prior } \\
\text { XRT }\end{array}$ & $\begin{array}{l}\text { Chemo lines } \\
\text { (n) }\end{array}$ & $\begin{array}{c}\text { PFS } \\
\text { (months) }\end{array}$ & $\begin{array}{c}\text { OS } \\
\text { (months) }\end{array}$ & $\begin{array}{l}\text { Best protocol } \\
\text { response }\end{array}$ \\
\hline 1 & $\mathrm{NET}^{1}$ & 1 & 1 & 0 & 0 & 1 & 2.1 & 13.5 & PD \\
\hline 2 & NET & 1 & 0 & 0 & 0 & 0 & 0.8 & 2.3 & PD \\
\hline 3 & $\mathrm{MTC}^{2}$ & 0 & 1 & 1 & 1 & 4 & 14.2 & 93.3 & SD \\
\hline 4 & MTC & 0 & 1 & 1 & 1 & 4 & 2.3 & 93.3 & SD \\
\hline 5 & MTC & 0 & 1 & 1 & 1 & 2 & 7.4 & 66.7 & SD \\
\hline 6 & MTC & 0 & 1 & 1 & 1 & 3 & 0.5 & 4.1 & PD \\
\hline 7 & MTC & 1 & 1 & 1 & 1 & 1 & 2.3 & 20.3 & PD \\
\hline 8 & MTC & 1 & 1 & 1 & 1 & 3 & 2.2 & 7.1 & PD \\
\hline 9 & NET & 1 & 1 & 0 & 1 & 3 & 0.5 & 0.5 & Death \\
\hline 10 & $\mathrm{ACC}^{3}$ & 1 & 1 & 1 & 0 & 1 & 6.4 & 17.5 & $M R$ \\
\hline 11 & MTC & 0 & 0 & 1 & 1 & 0 & 7.7 & 88.6 & PD \\
\hline 12 & ACC & 1 & 1 & 1 & 1 & 5 & 2.4 & 2.4 & Death \\
\hline 13 & $\mathrm{TCC}^{4}$ & 1 & 1 & 1 & 0 & 6 & 2.6 & 9.1 & $\mathrm{PD}$ \\
\hline 14 & ACC & 1 & 1 & 1 & 0 & 2 & 8.8 & 39.5 & PR \\
\hline 15 & MTC & 0 & 0 & 1 & 0 & 0 & 6.3 & 82.0 & SD \\
\hline 16 & ACC & 1 & 1 & 1 & 0 & 2 & 1.6 & 80.7 & PD \\
\hline 17 & ACC & 1 & 0 & 1 & 0 & 0 & 1.7 & 79.5 & PD \\
\hline 18 & Melanoma & 1 & 1 & 1 & 1 & 1 & 2.1 & 7.8 & PD \\
\hline 19 & ACC & 1 & 1 & 1 & 0 & 2 & 2.1 & 13.4 & PD \\
\hline 20 & ACC & 1 & 1 & 0 & 0 & 1 & 2.0 & 18.6 & PD \\
\hline
\end{tabular}

Patient-specific characteristics and outcomes. ${ }^{1} \mathrm{NET}$ - neuroendocrine tumor; ${ }^{2} \mathrm{MTC}$ - medullary thyroid carcinoma; ${ }^{3} \mathrm{ACC}-$ adrenocortical carcinoma; ${ }^{4} \mathrm{TCC}$ - Transitional cell carcinoma. PD - progressive disease; SD - stable disease; MR - minor response; PR - partial response. XRT - radiation therapy.; Chemo lines - number of prior chemotherapies. 
previously treated with standard therapy. The remaining 5 patients with ACC experienced progressive disease. No responses were seen in those patients with MTC, but 4 of 5 patients experienced stable disease (Table 4). However, all 4 patients entered the study with stable disease. With a median follow-up of 82 months, the median PFS was 2.3 months (95\% CI 2-2.7), with median OS of 18.6 months (95\% CI 8.8-28.4). Given the heterogeneity of the patient population, patient-level survival information is given in Table 4.

\section{Discussion}

In this phase I study, we have evaluated the safety of the combination of dacarbazine, capecitabine, and imatinib in metastatic endocrine cancers. The recommended dose regimen for a phase II trial is dacarbazine $250 \mathrm{mg} / \mathrm{m} 2$ daily on day 1-3, capecitabine $500 \mathrm{mg} / \mathrm{m} 2$ twice daily on days $1-14$, and imatinib $300 \mathrm{mg}$ daily on days $1-21$ of a 21 -day cycle. Dose-limiting toxicities most frequently included fatigue, dyspnea, and minor electrolyte and blood count abnormalities. The combination was otherwise tolerated well.

We also revealed evidence of activity of this regimen in ACC, even in the context of pretreated, refractory disease, a situation for which there are very limited effective therapies. Impact on overall survival is challenging to assess in the setting of a heterogeneous and uncontrolled patient population with respect to previous treatments, however, and overall survival was no better among the two responders than among the five non-responders.

Since this trial was initiated, multiple studies have investigated the in vitro and in vivo activity of imatinib-based regimens in MTC. Early studies of the in vitro effects demonstrated RET inhibition and death of oncogene-addicted MTC cells [14,33], but these studies demonstrated successful RET inhibition only at serum concentrations that could not be achieved with tolerable doses of imatinib, and subsequent clinical trials of imatinib monotherapy revealed no responses in MTC $[32,34]$. In one of these trials of imatinib monotherapy, patients with ACC were included as well, without evidence of clinical response [32]. Additional investigation of this agent in ACC, alone or in combination with cytotoxic chemotherapy has otherwise been lacking, making our combination entirely novel.

\section{Conclusion}

We present here the results of phase I trial of a combination of targeted therapy using imatinib with cytotoxic chemotherapy using capecitabine and dacarbazine in patients with advanced endocrine malignancies. Responses were rare, but occurred exclusively in patients with ACC, a cancer with limited effective therapies. These data should prompt consideration of a phase II trial of such a combination in this disease, given the paucity of other options. Alternatively, our hope is that these results will promote a deeper understanding of the disease biology in those patients who responded, allowing for the insightful and rational development of future targeted therapies.

\section{Competing interests}

DMH has no potential conflict of interest. ATP has received research support and speaking honoraria from Novartis. $\mathrm{AOH}$ has received research support from Exelixis, Eisai and Aztrazeneca. MA has no potential conflict of interest. PMH has received research support from Novartis and Roche. JCY receives research funding support from Novartis Oncology, and has consulting agreements with Novartis.

\section{Authors' contributions}

$\mathrm{DMH}$ analyzed and interpreted the data, drafted and revised the manuscript, and approved the final version. ATP designed the study, accrued patients, acquired data, provided critical manuscript revision, and approved the final version. $\mathrm{AOH}$ acquired and analyzed data acquisition, critically revised the manuscript, and approved the final version. MA acquired data, critically revised the manuscript, and approved the final version. JCY designed the study, accrued patients, acquired, analyzed, and interpreted data, critically revised the manuscript, and approved the final version. $\mathrm{PMH}$ designed the study, accrued patients, acquired, analyzed, and interpreted data, critically revised the manuscript, and approved the final version.

\section{Acknowledgments}

The authors would like to thank Ms. Carolyn Morrison for her administrative assistance.

\section{Funding}

Research support provided in part by Novartis Oncology.

\section{Author details}

'Department of Gastrointestinal Medical Oncology, The University of Texas M. D. Anderson Cancer Center, Houston, Texas, USA. ${ }^{2}$ Division of Hematology/Oncology, Department of Medicine, The Methodist Hospital, Houston, Texas, USA. ${ }^{3}$ Endocrine Neoplasia Unit, Instituto do Cancer do Estado de São Paulo Faculdade de Medicina da Universidade de São Paulo, São Paulo, Brazil. ${ }^{4}$ Instituto do Cancer do Estado de São Paulo Faculdade de Medicina da Universidade de São Paulo, São Paulo, Brazil.

Received: 6 March 2014 Accepted: 22 July 2014

Published: 2 August 2014

\section{References}

1. Hazard JB, Hawk WA, Crile G Jr: Medullary (solid) carcinoma of the thyroid: A clinicopathologic entity. J Clin Endocrinol Metab 1959, 19:152-161.

2. Brandi ML, Gagel RF, Angeli A, Bilezikian JP, Beck-Peccoz P, Bordi C, Conte-Devolx B, Falchetti A, Gheri RG, Libroia A, Lips CJ, Lombardi G, Mannelli M, Pacini F, Ponder BA, Raue F, Skogseid B, Tamburrano G, Thakker RV, Thompson NW, Tomassetti P, Tonelli F, Wells SA Jr, Marx SJ: Guidelines for diagnosis and therapy of MEN type 1 and type 2. J Clin Endocrinol Metab 2001, 86(12):5658-5671.

3. Mulligan LM, Kwok JB, Healey CS, Elsdon MJ, Eng C, Gardner E, Love DR, Mole SE, Moore JK, Papi L, Ponder MA, Telenius H, Tunnacliffe A, Ponder BAJ: Germ-line mutations of the RET proto-oncogene in multiple endocrine neoplasia type 2A. Nature 1993, 363(6428):458-460.

4. Boccia LM, Green JS, Joyce C, Eng C, Taylor SA, Mulligan LM: Mutation of RET codon 768 is associated with the FMTC phenotype. Clin Genet 1997 51(2):81-85.

5. Bolino A, Schuffenecker I, Luo Y, Seri M, Silengo M, Tocco T, Chabrier G, Houdent C, Murat A, Schlumberger M, Tourniaire J, Lenoir GM: RET mutations in exons 13 and 14 of FMTC patients. Oncogene 1995, 10(12):2415-2419.

6. Wohllk N, Cote GJ, Bugalho MM, Ordonez N, Evans DB, Goepfert H, Khorana S, Schultz P, Richards CS, Gagel RF: Relevance of RET proto-oncogene mutations in sporadic medullary thyroid carcinoma. J Clin Endocrinol Metab 1996, 81(10):3740-3745.

7. Eng C, Mulligan LM, Smith DP, Healey CS, Frilling A, Raue F, Neumann HP, Pfragner R, Behmel A, Lorenzo MJ, Stonehouse TJ, Ponder MA, Ponder BAJ: 
Mutation of the RET protooncogene in sporadic medullary thyroid carcinoma. Genes Chromosomes Cancer 1995, 12(3):209-212.

8. Hofstra RM, Landsvater RM, Ceccherini I, Stulp RP, Stelwagen T, Luo Y, Pasini B, Hoppener JW, van Amstel HK, Romeo G, Lips CJM, Buys CHCM: A mutation in the RET proto-oncogene associated with multiple endocrine neoplasia type $2 \mathrm{~B}$ and sporadic medullary thyroid carcinoma. Nature 1994, 367(6461):375-376.

9. Zedenius J, Larsson C, Bergholm U, Bovee J, Svensson A, Hallengren B, Grimelius L, Backdahl M, Weber G, Wallin G: Mutations of codon 918 in the RET proto-oncogene correlate to poor prognosis in sporadic medullary thyroid carcinomas. J Clin Endocrinol Metab 1995, 80(10):3088-3090.

10. Asai N, Iwashita T, Matsuyama M, Takahashi M: Mechanism of activation of the ret proto-oncogene by multiple endocrine neoplasia $2 \mathrm{~A}$ mutations. Mol Cell Biol 1995, 15(3):1613-1619.

11. Xing S, Smanik PA, Oglesbee MJ, Trosko JE, Mazzaferri EL, Jhiang SM: Characterization of ret oncogenic activation in MEN2 inherited cancer syndromes. Endocrinology 1996, 137(5):1512-1519.

12. Santoro M, Carlomagno F, Romano A, Bottaro DP, Dathan NA, Grieco M, Fusco A, Vecchio G, Matoskova B, Kraus MH, Di Fiiore PP: Activation of RET as a dominant transforming gene by germline mutations of MEN $2 A$ and MEN 2B. Science 1995, 267:381-383.

13. Marshall GM, Peaston AE, Hocker JE, Smith SA, Hansford LM, Tobias V, Norris MD, Haber M, Smith DP, Lorenzo MJ, Ponder BA, Hancock JF: Expression of multiple endocrine neoplasia 2B RET in neuroblastoma cells alters cell adhesion in vitro, enhances metastatic behavior in vivo, and activates Jun kinase. Cancer Res 1997, 57(23):5399-5405.

14. Cohen MS, Hussain HB, Moley JF: Inhibition of medullary thyroid carcinoma cell proliferation and RET phosphorylation by tyrosine kinase inhibitors. Surgery 2002, 132(6):960-966. discussion 966-967.

15. Scherubl H, Raue F, Ziegler R: Combination chemotherapy of advanced medullary and differentiated thyroid cancer. Phase II study. J Cancer Res Clin Oncol 1990, 116(1):21-23.

16. Wu LT, Averbuch SD, Ball DW, de Bustros A, Baylin SB, McGuire WP: Treatment of advanced medullary thyroid carcinoma with a combination of cyclophosphamide, vincristine, and dacarbazine. Cancer 1994, 73(2):432-436

17. Schlumberger M, Abdelmoumene N, Delisle MJ, Couette JE: Treatment of advanced medullary thyroid cancer with an alternating combination of 5 FU-streptozocin and 5 FU-dacarbazine. The Groupe d'Etude des Tumeurs a Calcitonine (GETC). Br J Cancer 1995, 71(2):363-365.

18. Di Bartolomeo M, Bajetta E, Bochicchio AM, Carnaghi C, Somma L, Mazzaferro V, Visini M, Gebbia V, Tumolo S, Ballatore P: A phase II trial of dacarbazine, fluorouracil and epirubicin in patients with neuroendocrine tumours. A study by the Italian Trials in Medical Oncology (I.T.M.O.) Group. Ann Oncol 1995, 6(1):77-79.

19. Bajetta E, Rimassa L, Carnaghi C, Seregni E, Ferrari L, Di Bartolomeo M, Regalia E, Cassata A, Procopio G, Mariani L: 5-Fluorouracil, dacarbazine, and epirubicin in the treatment of patients with neuroendocrine tumors. Cancer 1998, 83(2):372-378.

20. Petursson SR: Metastatic medullary thyroid carcinoma. Complete response to combination chemotherapy with dacarbazine and 5-fluorouracil. Cancer 1988, 62(9):1899-1903.

21. Wells SA Jr, Robinson BG, Gagel RF, Dralle H, Fagin JA, Santoro M, Baudin E, Elisei R, Jarzab B, Vasselli JR, Read J, Langmuir P, Ryan AJ, Schlumberger MJ: Vandetanib in patients with locally advanced or metastatic medullary thyroid cancer: a randomized, double-blind phase III trial. J Clin Oncol 2012, 30(2):134-141.

22. Kurzrock R, Sherman SI, Ball DW, Forastiere AA, Cohen RB, Mehra R, Pfister DG, Cohen EE, Janisch L, Nauling F, Hong DS, Ng CS, Ye L, Gagel RF, Frye J, Muller T, Ratain MJ, Salgia R: Activity of XL184 (Cabozantinib), an oral tyrosine kinase inhibitor, in patients with medullary thyroid cancer. J Clin Oncol 2011, 29(19):2660-2666

23. Dackiw AP, Lee JE, Gagel RF, Evans DB: Adrenal cortical carcinoma. World J Surg 2001, 25(7):914-926.

24. Kerkhofs TM, Verhoeven RH, Van der Zwan JM, Dieleman J, Kerstens MN, Links TP, Van de Poll-Franse LV, Haak HR: Adrenocortical carcinoma: a population-based study on incidence and survival in the Netherlands since 1993. Eur J Cancer 2013, 49(11):2579-2586.

25. Soon PS, McDonald KL, Robinson BG, Sidhu SB: Molecular markers and the pathogenesis of adrenocortical cancer. Oncologist 2008, 13(5):548-561.
26. Koch CA, Pacak K, Chrousos GP: The molecular pathogenesis of hereditary and sporadic adrenocortical and adrenomedullary tumors.

J Clin Endocrinol Metab 2002, 87(12):5367-5384

27. Hutter AM Jr, Kayhoe DE: Adrenal cortical carcinoma. Results of treatment with o, p'DDD in 138 patients. Am J Med 1966, 41(4):581-592.

28. Fassnacht M, Terzolo M, Allolio B, Baudin E, Haak H, Berruti A, Welin S, Schade-Brittinger C, Lacroix A, Jarzab B, Sorbye H, Torpy DJ, Stepan V, Schteingart DE, Arlt W, Kroiss M, Leboulleux S, Sperone P, Sundin A, Hermsen I, Hahner S, Willenberg HS, Tabarin A, Quinkler M, de la Fouchardiere C, Schlumberger M, Mantero F, Weismann D, Beuschlein F, Gelderblom H, et al: Combination chemotherapy in advanced adrenocortical carcinoma. N Engl J Med 2012, 366(23):2189-2197.

29. Fraenkel M, Gueorguiev M, Barak D, Salmon A, Grossman AB, Gross DJ: Everolimus therapy for progressive adrenocortical cancer. Endocrine 2013, 44(1):187-192

30. Berruti A, Sperone P, Ferrero A, Germano A, Ardito A, Priola AM, De Francia S, Volante M, Daffara F, Generali D, Leboulleux S, Perotti P, Baudin E, Papotti M, Terzolo M: Phase II study of weekly paclitaxel and sorafenib as second/third-line therapy in patients with adrenocortical carcinoma. Eur J Endocrinol 2012, 166(3):451-458.

31. Kroiss M, Quinkler M, Johanssen S, van Erp NP, Lankheet N, Pollinger A Laubner K, Strasburger CJ, Hahner S, Muller HH, Allolio B, Fassnacht M: Sunitinib in refractory adrenocortical carcinoma: a phase II, single-arm, open-label trial. J Clin Endocrinol Metab 2012, 97(10):3495-3503.

32. Gross DJ, Munter G, Bitan M, Siegal T, Gabizon A, Weitzen R, Merimsky O, Ackerstein A, Salmon A, Sella A, Slavin S: The role of imatinib mesylate (Glivec) for treatment of patients with malignant endocrine tumors positive for c-kit or PDGF-R. Endocr Relat Cancer 2006, 13(2):535-540.

33. de Groot JW, Plaza Menacho I, Schepers H, Drenth-Diephuis LJ, Osinga J, Plukker JT, Links TP, Eggen BJ, Hofstra RM: Cellular effects of imatinib on medullary thyroid cancer cells harboring multiple endocrine neoplasia Type 2A and 2B associated RET mutations. Surgery 2006, 139(6):806-814.

34. Frank-Raue K, Fabel M, Delorme S, Haberkorn U, Raue F: Efficacy of imatinib mesylate in advanced medullary thyroid carcinoma. Eur J Endocrinol 2007, 157(2):215-220

doi:10.1186/1471-2407-14-561

Cite this article as: Halperin et al:: A phase I study of imatinib,

dacarbazine, and capecitabine in advanced endocrine cancers. BMC Cancer 2014 14:561.

\section{Submit your next manuscript to BioMed Central and take full advantage of:}

- Convenient online submission

- Thorough peer review

- No space constraints or color figure charges

- Immediate publication on acceptance

- Inclusion in PubMed, CAS, Scopus and Google Scholar

- Research which is freely available for redistribution 